\title{
Activation Policies, New Modes of Governance and the Issue of Responsibility
}

\author{
Jean-Michel Bonvin \\ EESP, Chemin des Abeilles 14, CH-1010 Lausanne, Switzerland \\ E-mail:jmbonvin@eesp.ch
}

Most activation policies are based on a simplistic conception of responsibility: behaving responsibly coincides with quickly reintegrating the labour market. Local welfare agents are called to push beneficiaries to actively endorse this goal. But the issue of responsibility is much more complex. Drawing on Sen's capability approach, this article suggests that responsibilisation of recipients requires both empowerment and granting them more real freedom of choice on the labour market. Against the present trend toward hypertrophying individual responsibility, it calls for a more equilibrated balance between individual and social responsibility. The objective is not to define an impracticable ideal of responsibility, but to provide a yardstick for assessing activation programmes.

The trend towards activation in contemporary social policies, what Bob Jessop called, in a somewhat provocative way, the Schumpeterian workfare state (Jessop, 1994), is by now well documented. In the last decades, a great variety of reforms were passed in most OECD countries with a view to transforming welfare into an instrument of activation (e.g. RMI in France, TANF in the United States, the New Deal programmes in the UK, etc.). This evolution entails a threefold transformation: (a) social expenses are to be activated and become productive in line with the social investment state; (b) benefit recipients should be induced (via 'making work pay' programmes) or constrained (via workfare schemes) to quickly reintegrate the labour market; (c) local agents of the welfare state as well as private contracted-out providers are to act as intermediaries towards such quick and possibly long-lasting professional reinsertion. At the core of all these changes, there is an implicit and undisputed view of what objectives responsible individuals should pursue within the field of social policies. In a nutshell, these targets are strongly connected with increasing the employment rates at a macro level, and accelerating reintegration into the labour market at a micro level. As a result, acting responsibly coincides with getting people back to work as quickly as possible. This issue being settled, the challenge faced in social policies boils down to finding the most efficient modes of governance in order to promote such responsible behaviour among the local agents of the welfare state and the beneficiaries. In other terms, how can these actors be induced or constrained (via sticks and/or carrots) to endorse such a view of responsibility? In this way, the issue of governance is reduced to a mere technical question of efficiency, and all political and normative issues dealing with equity, social justice or the adequate combination of individual and collective responsibility are left aside. This article contends that the issue of responsibility is much more complex and needs to be carefully re-examined. Drawing on Sen's capability approach (Sen, 1999), the first section roughly identifies 
the main prerequisites of genuinely responsible behaviour, i.e. adequate resources and opportunities on the one side, freedom of choice on the other one. The following two sections apply this analytical and normative framework to the case of local agents and beneficiaries in activation policies such as workfare programmes, training measures, subsidised jobs or any other form of professional guidance. This provides an assessment of specific activation programmes (i.e. what is the meaning and content of responsible behaviour purported in them?) and modes of governance (i.e. how is responsibility distributed between the central administration, the local agents and the beneficiaries?) against the capability framework of responsibility. The final section synthesises the main findings of the article and concludes.

\section{The prerequisites of responsibility in the capability approach}

The capability approach insists on two necessary preconditions of responsible behaviour: adequate means and power to act and real freedom to choose one's way of living. Hence, if someone is not adequately equipped in terms of capacity to act, s/he cannot be considered as truly responsible. In Sen's words, the responsible person should then be provided with sufficient resources or commodities (e.g. goods, services, incomes, social transfers, etc.) and with appropriate factors of conversion (i.e. competencies, available opportunities, etc.) allowing her or him to convert these resources into real capacity to act. However, such empowerment is not sufficient to foster responsibility. Indeed, if a person adequately empowered is not free to use his or her capacity in the way s/he chooses to (or to use Sen's recurrent formula, 'in the way s/he has reason to value'), it still does not make sense to speak of responsible or irresponsible behaviour. In Sen's language:

Without the substantive freedom and capability to do something, a person cannot be responsible for doing it. But actually having the freedom and capability to do something does impose on the person the duty to consider whether to do it or not, and this does involve individual responsibility. In this sense, freedom is both necessary and sufficient for responsibility. (Sen, 1999: 284, emphasis added)

In the field of social policy, the enhancement of the capacity to act, or empowerment, entails taking into account at least two dimensions: the resources made available (i.e. are they sufficient in amount and duration? What conditions are recipients subject to?); and the opportunities, e.g. jobs or training, open to the recipients (i.e. what is the quantity and quality of opportunities available?). In actual active labour market programmes (ALMPs) in different countries, these two issues of resources and opportunities are tackled in a great variety of ways. Indeed, if activation always implies a higher focus on individual responsibility, this may coincide either with more extended collective interventions or with the retreat of the state. And this variety within the field of ALMPs indicates a significant diversity in the ways to conceive the balance between individual and collective responsibility, which heavily impacts on local agents' practices and on their expectations towards beneficiaries. With regard to these local actors, Sen's capability approach sets a very high standard of responsibility. Indeed, genuine freedom of choice, which is a prerequisite for responsible behaviour in the capability approach, depends on the availability of the three options identified by Hirschman (1970) - loyalty, exit and voice. Local actors, i.e. welfare agents and beneficiaries, should not be constrained to loyalty, 
but should be allowed not to comply with the administrative view of activation without incurring unbearable penalties as a consequence (i.e. exit), and they should also be able to negotiate and somewhat influence the content of ALMPs (i.e. voice). Hence, the extent to which local actors are allowed to reinterpret the centrally designed conception of activation and adjust it to local circumstances is a necessary condition of their behaving responsibly.

To sum up, for Sen (1999), responsibility necessitates a combination of capacity to act (opportunity freedom) and freedom to choose (process freedom). The next two sections examine these two dimensions of responsibility in the case of activation policies.

\section{Responsibility and capacity to act in activation policies}

The local actors' capacity to act depends on at least three complementary dimensions. First, the way to organise financial redistribution within the welfare state clearly impacts on the conception of responsibility in social integration policies. Indeed, according to the amount and duration of social security benefits, as well as to the eligibility conditions and other requirements imposed on recipients, the expectations in terms of responsibility will vary significantly. In countries such as the US or the UK, where benefits are envisaged as potential sources of poverty traps, redistribution of cash resources is limited both in amount and duration, and strict conditionalities are imposed (Handler, 2004; King, 1999). This implies that benefit systems are carefully reviewed in order to eliminate such traps and set up appropriate financial incentives. In these countries, a specific normative reference is imposed with regard to the link between cash redistribution and activation (i.e. too many redistributed resources equals less capacity or willingness to act on behalf of the recipients), and competing views of the 'welfare-activation' nexus are discarded by decision-makers (Bonvin, 2006). Such ambition to make welfare policies more dissuasive has a strong influence on local welfare agents who have to work in shorter time spans and are pushed to privilege quick-fix remedies and avoid long-term schemes aiming at long-lasting professional reintegration (Peck and Theodore, 2000). This especially holds for the most disadvantaged groups. Indeed, retrenchment measures inducing benefit reductions often coincide with a corresponding reduction of the time available for activating recipients, and a consequent risk of creaming and selective practices at local level (Benarrosh, 2006). By contrast, programmes providing generous and long-lasting benefits, e.g. in Scandinavian countries or in Switzerland, endorse the opposite view (i.e. more redistributed resources equals more capacity to act), which allows for more ambitious and longer-term interventions at local level. This opposite conception of cash redistribution also entails another division of responsibilities between individual and collective actors: whereas, in the former instance, responsibility is first and foremost a matter of individual will, with the state mostly playing a moralising part in this direction, it is here envisaged as a joint task of the individual and the state. In much the same spirit, Gazier (1999) envisages the enhancement of employability as the common duty of the individual job-seekers and the public bodies, what he called 'interactive employability'.

Second, the design and content of activation measures is also far from uniform. In strictly quantitative terms, the amount of resources devoted to ALMPs greatly differs among countries (EC, 2006). And the objectives pursued in such programmes range from pushing people back to work or enhancing their human capital and qualifications to the creation of temporary jobs in public administration, the payment of job subsidies 
to employers on the private labour market or measures designed to help create selfemployment. As a result, there is a great variety of services provided within public employment services (as evidenced for instance by Personnaz et al., 2007). Thus, ALMPs may endorse very different views of activation promoting respectively work, employability, occupation, or looser objectives such as autonomy or social integration (for an illustration of such diversity in OECD countries, see Tergeist and Grubb, 2006). And this diversity in turn plays a key role in shaping local agents' practices. Indeed, if the normative reference underlying ALMPs focuses on the development of qualifications, and considerable financial resources are mobilised to this purpose, long-term programmes may be designed to foster durable professional integration in a qualified job. By contrast, if work is considered to be a short-term objective with a view to reducing the caseload and public expenses, reintegration into the labour market will take less account of the issue of job quality (Bonvin and Moachon, 2007). Depending on the normative reference of activation selected, local agents' responsibility will then coincide either with pursuing quick professional reintegration (possibly in a precarious job), or with promoting a longterm and durable reintegration in an attractive job. A key issue in this respect is linked to the degree of precision of the administrative view of activation: the more specified it is (e.g. all recipients should go back to work as quickly as possible), the less margin of manoeuvre is left to local agents, and consequently the less scope for responsibility; by contrast, the less specified it is (e.g. promote all recipients' social integration or autonomy), the more margin of manoeuvre and the higher the scope for responsibility, provided adequate funding and means are made available. In applying the capability approach to responsibility, the problem is not activation in itself but the ambition to impose one and the same conception of activation on all beneficiaries (Bonvin, 2005; Bonvin and Farvaque, 2007).

Finally, the capacity to act also depends on the opportunities for social and professional integration open to benefit recipients. In most OECD countries, market actors are increasingly deemed responsible for job creation. As a consequence, the availability of working opportunities strongly depends on these market actors' readiness and ability to create enough jobs. In this context, the state is called to re-deploy its interventions from a market-steering to a market-supporting orientation (Levy, 2006), and this may be achieved in a plurality of ways. The state might be confined to creating the appropriate conditions to foster entrepreneurship and promote competitiveness and job creation (e.g. via financial incentives such as job subsidies). Or it can act as a kind of last resort employer via the development of an extended public sector (which has somehow been the case of Scandinavian countries, whose share of public employment amounts to the double of the OECD average - cf. Esping-Andersen, 1999). Or it may choose to subsidise the creation of a so-called secondary labour market or of an extensive third sector. These various options impact differently on the quality and quantity of working opportunities, and especially on their availability to diverse groups of benefit recipients. If the market is the ultimate provider of working opportunities, access to such jobs may prove difficult for the most disadvantaged groups. By contrast, if job creation is a task commonly assumed by the market, the state and the third sector, then these groups will have more opportunities of professional integration in adequate conditions.

To sum up, with regard to the 'capacity to act' side of responsibility, a high level of resources, a great variety of activation programmes aiming at providing appropriate solutions for all target groups, as well as plenty of opportunities created by diverse 
actors (the market, the state and the third sector) qualify as more capability-friendly than their opposite, i.e. few resources, very specified activation schemes and opportunities provided mainly by the market. Hence, the way these three issues (resources, content of ALMPs, opportunities) are framed determines to a large extent the possibility to efficiently support all target groups, and it defines the balance between collective and individual responsibility and the version of the enabling state that will prevail in the end (Gilbert, 2004). If equipped with appropriate resources and opportunities, local welfare agents and beneficiaries may rightly be considered as accountable for their actions; in contrast, public policies marked by retrenchment offer poor resources and opportunities, and requirements imposed on local agents and beneficiaries to behave responsibly appear as much more questionable.

\section{Responsibility and freedom to choose in employment services}

However, responsibility comprises a second dimension in the capability perspective, namely real freedom to choose. The main issue at stake here is whether the modes of governance used to monitor the relationship between the central and the local level in activation policies leave enough margin of manoeuvre to local actors. Two levels of contractualism will be considered in the next two subsections: between central level and local agents on the one side, between local agents and beneficiaries on the other side.

\section{Contractualism between central administration and local actors}

Bureaucratic provision of services, along standardised lines of intervention, is not adapted to ALMPs insofar as it is unable to take into account local and individual circumstances (Varone and Bonvin, 2004). Therefore, bureaucracy needs to be substituted by other modes of governance in which local agents are called to take on more responsibilities. However, in order to avoid the potential arbitrariness of purely local decisions, the state has to monitor these interventions, i.e. to secure that the beneficiaries' fundamental rights are respected and that local action keeps in line with centrally designed objectives. With regard to this role of the central state in ALMPs, three configurations can be identified (cf. Bonvin and Moachon, 2007; Borghi and Van Berkel, 2007; Newman, 2007) that I suggest to name 'hierarchical', 'marketised' and 'capability-friendly'.

In the first one, the state keeps a strong control over local practices, mainly via the tools of new public management: quantitative objectives are fixed with financial penalties for local agents not fulfilling them, budgets are allotted on a short-term and revisable basis, precise indicators of performance are elaborated, etc. In its most extreme form, this pattern reinforces the features of bureaucratic action: not only the means and processes of public action are strictly defined and controlled via input indicators, but also the results are carefully monitored via output indicators. As a consequence, local agents are not only responsible for respecting the processes defined by the central administration, but they are also held accountable for unsatisfactory results and have to abide by the sanctions imposed on them. The knowledge and competence of local actors is not genuinely recognised in this configuration. Management by objectives within the public administration, when it is implemented along these strict lines, is certainly the purest example of this pattern (ALMPs 
in Switzerland go a long way on this managerial path - see Bonvin and Moachon, 2007 but this is a common way of governing employment public services as emphasised by Sol and Westerveld, 2005a). Indeed, the central state has more control over local public agents in its jurisdiction than over contracted-out private providers on whom input indicators are more difficult to impose. However, private suppliers of social services, be they for profit or not, may also be subjected to this hierarchical configuration, especially when their financial dependency vis-à-vis the state is very high. Under these circumstances, they are unable either to contest the administrative view of activation (i.e. Hirschman's (1970) voice option) or to refuse the conditions defined in the contract (i.e. exit). In such cases, loyalty is the only available option also for local private actors. Viewed from the capability perspective, local actors do not enjoy substantive freedom of choice in this configuration, and therefore cannot be held responsible for what they do. ${ }^{1}$

In the second instance, the state retreats and leaves a higher margin for manoeuvre to local actors. In such a model, the state as a provider is considered to have failed. Thus, it must leave to market actors the responsibility of running efficient professional reintegration services. But it remains responsible for providing sufficient funding and for evaluating the efficiency of local action against rough indicators of performance (e.g. reinsertion rates). Competition between service providers, it is claimed, will improve the quality of the services as well as the quality-price ratio. As evidenced by Sol and Westerveld (2005b), the potential advantages of this formula are greater flexibility in the use of contractors, focus on outcomes rather than processes, and lower costs. All these are supposedly connected with higher efficiency in the pursuit of centrally fixed targets. In this model, normative issues related to activation are considered as the exclusive prerogative of policymakers, and the whole problem is reduced to a matter of technical efficiency in implementing ALMPs. Market modes of governance are certainly a good tool to improve efficiency via competition and tendering, but due to their tendency to lower costs (i.e. give precedence to cheaper providers for the same tasks) and standardise programmes, they cannot guarantee that an adequate view of activation, i.e. one taking into account local circumstances and individual features, will be selected at local level. Indeed, such a configuration based on market modes of governance risks favouring creaming and selective practices, i.e. the local providers will focus on the beneficiaries that allow them to reach the targets (fixed in the provision agreement) at the expenses of more disadvantaged groups (Sol and Westerveld, 2005a, provide illustrations of this risk).

In the third instance, central administration and local agents act as partners in the implementation of ALMPs. The central state keeps an essential twofold function as a guarantor of the beneficiaries' fundamental rights and as a monitoring body of local action, but these tasks are interpreted in such a way as to promote local actors' active participation in the implementation of ALMPs. This entails a twofold move from bureaucratic public action and from the hierarchical model identified above: first towards a more participative definition of the aims and indicators of public action, second towards the formulation of more incomplete objectives in order to leave a higher margin for manoeuvre to local actors. For instance, if the objectives of ALMPs are not defined in terms of employment rates, but in terms of improving the beneficiaries' autonomy, then the scope for responsible local action is extended. Hence, an incomplete definition of activation at the central level makes space for a 'politics of needs interpretation' at the local level (Fraser, 1989). This third configuration is barely mentioned in Sol and Westerveld's survey (2005a) of contractual practices in employment services. ${ }^{2}$ Yet, this innovative path, 
which means less controlling power for the central administration and more genuine autonomy for local actors, is not incompatible with the pursuit of efficiency in ALMPs. Quite the contrary, by giving local agents the means and freedom to act responsibly (in line with the capability approach), it makes them truly responsible and accountable for the results obtained. ${ }^{3}$ In this last pattern, responsibility and accountability do not boil down to efficient implementation of exogenously defined objectives, but encompass active involvement in the definition of the most adequate modes of activating people. This implies another distribution of power between the state, local agents and beneficiaries, more in line with the so-called participative model of new public management (Monks, 1998). According to the capability approach, contractualism in employment services should leave the restrictive view of principal-to-agent relationships and embrace a more participative conception of public action.

\section{Contractualism between local agents and beneficiaries}

The place of the benefit recipient in individualised activation policies needs also to be questioned. In the hierarchical pattern, the beneficiary's responsibility is fostered via obedience to the injunctions of the central administration relayed by local agents acting as 'driving belts'. Individual wishes and expectations are taken into account insofar as they correspond to this specific conception of activation, otherwise it is the local agents' task to reform them and make them coincide with the institutional expectations. The chain of governance is conceived as a top-down transfer of specific normative contents that need to be endorsed and actively pursued by local agents and beneficiaries alike (Bonvin and Moachon, 2007).

In certain instances of the marketised configuration, the individual is equipped with more freedom of choice via the provision of vouchers or personal budgets (e.g. Bruttel, 2005). Beneficiaries can express their wishes more freely since they are allowed to choose their ALMPs. At the core of such practices, there are two postulates: first, the respect of the beneficiary's freedom of choice passes via the attribution of a freely disposable income, i.e. the issue of freedom of choice is framed in terms of consumer choice; second, it is assumed that a free choice by consumers, in this case benefit recipients, will result in higher quality of the services provided by private employment agencies. As Sol and Westerveld (2005b) emphasise, there are many practical obstacles to be overcome before fulfilling this twofold promise: the great similarity of the solutions provided in marketised employment services (which considerably restricts the freedom of choice), the asymmetry of information about the quality of services (which facilitates cheating on customers), and most importantly the frailty of the recipient's consumer position. As a matter of fact, the truly contractual relationship is not between the beneficiary and the provider, but between the state, responsible for funding vouchers and personal budgets, and the private provider. The key issue lies here in the capacity of the beneficiary to influence the definition and content of ALMPs, and it is doubtful whether s/he will really be allowed to have his or her say in this respect. In comparison with the hierarchical pattern, this configuration takes some steps towards giving more responsibility to benefit recipients (additional means are provided and some freedom of choice is granted), but it still remains in the middle of the road. 
In the capability-friendly model, the beneficiary is considered as an active citizen and invited to take part in the definition of ALMPs and in their implementation. Provided adequate means are granted to empower her and improve her capacity to act, this pattern engages her in a self-reflexive process (Borghi and Van Berkel, 2007) on how to best develop her capabilities. The main difference with the marketised pattern lies in the possibility to co-define and co-implement activation programmes. The capabilityfriendly model recognises that rationality is not detained by single actors presumably more competent than all others, and that the informational role of multi-levelled actors is essential in any actual policy-making situation. If rationality is distributed or shared in such a way, then local employment agencies have to be seen as 'informational agencies' (White, 1990), and beneficiaries are informational sources to be mobilised in the collective definition of ALMPs. What matters then is not how the central state may impose more efficiently its own normative references on local actors, it is rather how it can promote the co-definition and co-implementation of activation programmes at local level.

With regard to the 'freedom to choose' side of responsibility, our analysis shows the importance to take into account local expertise and knowledge, as well as local circumstances and individual preferences when it comes to designing and implementing ALMPs. The role of the state, no more as a provider, but as a guarantor and a monitoring body, is key in this respect. Indeed, local action by itself will not necessarily result in enhancing the capabilities of all local actors, i.e. local providers and all groups of beneficiaries alike. A fine-tuned balance needs to be found in the way the central level connects to local action. In the capability perspective, the normative references defined by central bodies ought to be both incomplete in order to allow for local initiatives, and quite strict and precise in defining fundamental rights, in order to prevent local arbitrariness and all forms of undue intrusion in the beneficiaries' private sphere that may lead to 'shameful revelations' (Wolff, 1998).

\section{Conclusion}

The capability approach provides the tools for a renewed analysis of the issue of responsibility in activation policies. First, on the 'capacity to act' side of responsibility, an application of Sen's (1999) perspective allows for an identification of the importance of providing sufficient resources and adequate opportunities to local ALMP agents and beneficiaries. If they are not appropriately equipped in these two key respects, the call for responsibility remains formal in the Marxist sense, i.e. local actors are invited to behave responsibly, but they do not have the necessary means for that purpose. In the capability approach, collective interventions are envisaged as necessary for fostering individual responsibility, and not as factors producing dependence and irresponsibility. This implies, for instance, that workfare programmes and all measures exacerbating individual responsibility without providing adequate collective support are not able to promote responsibility as it is defined in the capability perspective. Besides, the degree of precision of the administrative definition of activation also plays a key role with regard to the issue of responsibility. Indeed, if restricted to very specified solutions such as quick reintegration into the labour market, the centrally designed definition of activation does not allow for taking into account all local circumstances and individual characteristics 
and preferences. Such precise targets may prove inappropriate or even unrealistic, especially for the most disadvantaged groups. In contrast, unspecified objectives, such as the enhancement of capabilities, allow for more diversified interventions at local level. Return to work or the promotion of employability are not discarded altogether, but they are envisaged as possible solutions amid a more extensive set of ALMPs. I therefore contend that too precise a definition of activation entails selective practices at local level, which impedes the most disadvantaged groups to enjoy the capacity to act responsibly. Thus, in this first respect, three prerequisites are identified for a successful promotion of responsibility among local actors: sufficient resources, adequate opportunities and broad definitions of activation.

Second, the 'freedom to choose' dimension of responsibility greatly depends on the way to organise coordination between the different actors involved in activation policies. This encompasses the relationships between central administration and local level on the one hand, and local providers and individual beneficiaries on the other hand. If one of these levels prevails over the others and imposes its own specific definition of activation, freedom of choice gets reduced and, consequently, the conditions for genuine responsibility are not adequately fulfilled. In the capability perspective, all such interventions are counterproductive when it comes to fostering responsibility, and the role of the state is to prevent them. What is suggested is not an unconditional respect for the local agent's and the beneficiary's freedom to choose (whatever their preferences), but the opportunity offered for them to take an active part in the design and implementation of ALMPs and to make their voice heard.

In the capability approach, the assessment of responsibility in activation policies necessitates taking into account two main questions: (a) the balance between individual and collective responsibility, (b) how the two core issues - capacity to act and freedom to choose - are framed within this context. The objective is not to define an impracticable ideal of responsibility, but to provide a yardstick for assessing activation programmes (e.g. given specific resources and opportunities, and a determined degree of freedom to choose, what level of individual responsibility can reasonably be expected from local actors?) and to suggest possible improvements in the direction of fostering more genuine responsibility among the beneficiaries. In our view, such a conception calling for more realistic claims to individual responsibility could well represent the way out of the pitfalls (paradoxical injunctions, double binds, etc.) of most present managerialist practices.

\section{Notes}

1 In Newman's typology (2007), the patterns of 'hierarchical governance' and 'managerial governance' are the most likely to range under this first category.

2 In Switzerland, some cantons privileging the preferred supplier model take some steps towards this pattern, but there is still a long way to go (Bonvin and Moachon, 2007).

3 This configuration is similar to the 'participative bureaucratic management and administration model' identified in Borghi and Van Berkel (2007) as well as to the 'network governance' in Newman's typology (2007). 


\section{References}

Benarrosh, Y. (2006), Recevoir les chômeurs de l'ANPE: L'institution entre don et contrat, Paris, L'Harmattan.

Bonvin, J.-M. (2005), 'La démocratie dans I'approche de Sen', L'économie politique, 27: 24-36.

Bonvin, J.-M. (2006), 'Assessing the European social model against the capability approach', in M. Jepsen and A. Serrano (eds), Unwrapping the European Social Model, Bristol: The Policy Press, pp. 213-32.

Bonvin, J.-M. and Farvaque, N. (2007), 'A capability approach to individualised and tailor-made activation', in R. Van Berkel and B. Valkenburg (eds), Making it Personal: Individualising Activation Services in the EU, Bristol: The Policy Press, pp. 45-66.

Bonvin, J.-M. and Moachon, E. (2007), 'The impact of contractualism in social policies: the case of active labour market policies in Switzerland', International Journal of Sociology and Social Policy, 27, 9/10, 401-12.

Borghi, V. and Van Berkel, R. (2007), 'Individualised service provision in an era of activation and new governance', International Journal of Sociology and Social Policy, 27, 9/10, 413-24.

Bruttel, O. (2005), 'Delivering active labour market policy through vouchers: experiences with training vouchers in Germany', International Review of Administrative Sciences, 71, 3, 391-404.

Esping-Andersen, G. (1999), Social Foundations of Postindustrial Economies, Oxford: Oxford University Press.

European Commission (2006), Employment in Europe 2006, Luxembourg: Office for Official Publications of the European Communities.

Fraser, N. (1989), Unruly Practices, Cambridge: Polity Press.

Gazier, B. (ed.) (1999), Employability: Concepts and Policies, Report 1998, Luxembourg: European Employment Observatory Research Network, European Commission.

Gilbert, N. (2004), Transformation of the Welfare State: The Silent Surrender of Public Responsibility, Oxford: Oxford University Press.

Handler, J. (2004), Social Citizenship and Workfare in the United States and Western Europe: The Paradox of Inclusion, Cambridge University Press.

Hirschman, A. O. (1970), Exit, Voice and Loyalty: Responses to Decline in Firms, Organizations and States, Cambridge, MA: Harvard University Press.

Jessop, B. (1994), 'The transition to post-fordism and the Schumpeterian workfare state', in R. Burrows and B. Loader (eds), Towards a Post-Fordist Welfare State?, London: Routledge, pp. 13-37.

King, D. (1999), In The Name of Liberalism: Illiberal Social Policy in the United States and Britain, Oxford: Oxford University Press.

Levy J. (ed.) (2006), The State after Statism, New State Activities in the Age of Liberalization, Cambridge, MA and London: Harvard University Press.

Monks, J. (1998), 'La nouvelle gestion publique: boîte à outils ou changement paradigmatique?', in $M$. Hufty (ed.), La pensée comptable, Genève/Paris: Les nouveaux cahiers de I'IUED/PUF, pp. 77-89.

Newman, J. (2007), 'The 'double dynamics' of activation: institutions, citizens and the remaking of welfare governance', International Journal of Sociology and Social Policy, 27, 9/10, 364-75.

Peck, J. and Theodore, N. (2000), 'Beyond "employability"', Cambridge Journal of Economics, 24, 6, 729-49.

Personnaz, E., Segas, S. and Darmon, I. (2007), Advice and Guidance Service for Out-of-Work Individuals and Workers 'at Risk' in Five European Countries: An Exploratory Typology, Volume I, Marseille/Barcelona: CEREQ/ICAS, http://www.guidanceineurope.com/doc/GuidanceinEurope\% 20wp3\%20deliv\%203\%20vol1\%20FINAL\%20EN.pdf

Sen, A. K. (1999), Development as Freedom, Oxford: Oxford University Press.

Sol, E. and Westerveld, M. (eds) (2005a), Contractualism in Employment Services: A New Form of Welfare State Governance, The Hague: Kluwer Law International.

Sol, E. and Westerveld, M. (2005b), 'Contractualism: concluding remarks', in E. Sol and M. Westerveld. (eds), Contractualism in Employment Services: A New Form of Welfare State Governance, The Hague: Kluwer Law International, pp. 383-402. 
Tergeist, P. and Grubb, D. (2006), Activation Strategies and the Performance of Employment Services in Germany, the Netherlands and the United Kingdom, Paris: OECD Social, Employment and Migration Papers.

Varone, F. and Bonvin, J.-M. (2004), La nouvelle gestion publique, special issue of Les politiques sociales, $1-2$.

White, M. (1990), 'Information et chômage des jeunes', Sociologie du travail, 4, 529-41.

Wolff, J. (1998), 'Fairness, respect, and the egalitarian ethos', Philosophy and Public Affairs, 27, 2, 97-122. 